\title{
Textbook Evaluation as a Means of Discovering Learners' and Teachers' Needs
}

\author{
Svetlana Bogolepova \\ National Research University Higher School of Economics \\ Correspondence concerning this article should be addressed to Svetlana Bogolepova, National \\ Research University Higher School of Economics, Malaya Pionerskaya, 12, Moscow, Russian \\ Federation, 115054.E-mail: tsbogolepova@hse.ru
}

\begin{abstract}
Needs analysis is considered an essential step which normally precedes English for Academic Purposes course design. It allows course developers to identify the tasks the target audience has to complete, and the skills they need to master. Based on the experience of the 'English for Academics' textbook writing project, the paper shows that needs analysis can be extended to the materials evaluation stage of textbook development. The piloting undertaken at this stage involved a questionnaire which required qualitative and quantitative responses from teacher and learner participants. The respondents were encouraged to evaluate different aspects of the course implementation, e.g.timing, relevance, difficulty, sequence, clarity of instructions, etc., and suggest improvements. The questionnaire was analysed which provided course developers with the opportunity to identify additional learners' needs and to explore teachers' needs and expectations, which in many respects coincided with each other. Consequently, the learning and teaching materials were restructured in accordance with the evaluation. The changes which were introduced into the textbook and the Teachers' Notes are described. It is concluded that piloting can be an instrument to expose both pedagogical and linguistic needs, thus, providing for the triangulation of the methods and reliability of the results.
\end{abstract}

Keywords: materials design, materials evaluation, needs analysis, triangulation

Needs analysis is considered central to English for Academic Purposes (EAP) course development (Hutchinson \& Waters, 1997; Hyland, 2006; Jordan, 2002). Normally needs analysis is carried out before a course is designed with the purpose of understanding what should be included in the course. It allows course designers to make it learner-centered and concentrate on the development of skills appropriate for a particular audience. As Hamp-Lyons (2001, p. 126) argues, EAP 'begins with the learner and the situation, whereas general English begins with the language.'

This paper will consider a different stage of textbook development, the materials evaluation stage in particular. It will be demonstrated that learners' needs are discovered at this stage as well, and they are not similar to the ones exposed at the needs analysis stage. Apart from this, it will be shown that teachers' needs and expectations can be revealed at the piloting stage. These discoveries allow for further improvements of the materials both from the contextual and the pedagogical point of view.

However, before turning to the description of the evaluation stage and the inferences made after the consideration of its results, it is necessary to briefly outline the current understanding of needs analysis and provide the background of the textbook writing project within which the research was conducted.

\section{Materials and Methods}

\section{Literature Review}

There is no uniform view on what constitutes needs analysis. Needs analysis is viewed as both a process aimed at 'determining the needs for which a 
learner or group of learners requires a language and arranging the needs according to priorities' (Richards \& Schmidt, 2010, p. 399), and techniques 'for collecting and assessing information relevant to course design' (Hyland, 2006, p. 73). Flowerdew (2013) elaborates saying that those are not only needs, but also lacks and wants which are brought out into open. Jordan (1997, p. 28) suggests that needs analysis in EAP situations should reveal the level to achieve, language to learn, study situations and related study skills, as well as the existing level and the gap in skills which needs to be bridged. Jolly and Bolitho go even further saying that 'the most effective materials are those which are based on thorough understanding of learners' needs, that is their language difficulties, their learning objectives, their style of learning, the stage of their conceptual development... ' (Bolitho \& Jolly, 2011, p. 128). However, the importance of needs analysis is uniformly recognised as 'a rigorously conducted NA is likely to provide a solid foundation needed for effective language teaching course design and delivery' (Lake, Long \& Serafini, 2015, p. 25).

There are multiple ways in which needs analysis can be carried out. Long (2005, p. 31) describes the following methods: non-expert and expert intuitions, unstructured and structured interviews, surveys and questionnaires, language audits, observations, diaries, analysis of corpora and discourse, etc. He emphasises the importance of professionally conducted needs analysis. The researcher argues that, though learners provide useful information about their occupational needs and preferences, they may be ineffective in 'determining the language involved in functioning successfully in their discourse domains' (Long, 2005, p. 20). Therefore, it is the materials developers' task to analyse the questionnaire results, draw conclusions about the learners' needs and decide on the target discourse features.

Researchers (Long, 2005; Hyland, 2009) claim that the outcomes of a needs analysis are more objective when the triangulation method is implemented, that is information from various sources is considered. Moreover, 'to increase reliability and validity, data should ideally be collected from two or more sources using two or more methods' (Lake, Long \& Serafini, 2015, p. 12).

It is necessary to acknowledge that needs analysis cannot be the only source of information for course designers to base their decisions on; more factors have to be taken into account (West, 1994). For example, in the case of the 'English for Academics' project, the experience of which is going to be discussed in the article, both authors' perceptions about what kind of language and skills academics need to master to successfully function in the academic environment and the survey results dictated the primary choice of materials and tasks.

However, Hyland (2006, p. 74) points out that needs analysis should be ongoing and dynamic. Normally, teachers are responsible for adjusting materials to the immediate needs of their learners. Provisioning for such kind of ongoing analysis while the materials are still being developed may be the way to better cater for learners' needs.

\section{Background}

Hyland and Hamp-Lyons (2002) argue that EAP has already expanded far beyond university level learning, and now it encompasses more than instruction of learners on how to successfully study in an Englishspeaking environment. Among other concerns, the researchers highlight 'the English language skills of nonnative English speaking academics, especially those teaching and researching in non-English language countries' (Hyland \& Hamp-Lyons, 2002, p. 4). For Russia, which has entered the Bologna process fairly recently and is still undergoing the internationalisation of tertiary education, the ability of academic staff to function in English remains a topical issue. Researchers and university teachers are required to publish in English and to participate in international events, though they do not always possess the necessary skills and knowledge.

The 'English for Academics' course was developed by a group of Russian university teachers under the supervision of the British expert Rod Bolitho within the British Council (Russia) project. Its aim was to equip academic staff with the skills and to provide them with the language to become part of the international academic community. In this article, the process of the development of 'English for Academics. Book 1' (Bezzabotnova et al., 2014) will be in focus. The authoring team agreed to divide the first book in the course into four modules, each catering for the development of the appropriate microskills within the four major skills. The author of the article mostly contributed to the development of the materials for the Writing Module, which deals with academic correspondence, summary, abstract and grant application writing.

Jolly and Bolitho (2011, p. 113) suggest the

following stages of textbook development:

1. Identification of need

2. Exploration of need

3. Contextual realisation of materials

4. Pedagogical realisation of materials

5. Student use of materials

6. Materials evaluation

The need for a course to teach English to individuals involved in academia (i.e. university teachers, researches and administrators) in Russia 
was revealed in Frumina and West's baseline study (Frumina \& West, 2012). They came to the conclusion that what really hindered the internationalisation of higher education in Russia was a low level of the English language of university academic staff. It is poor English language proficiency that inhibits Russian academics' dissemination and publication of research and prevents them from providing courses for international students. Frumina and West highlight the necessity for the development of a textbook which would suit academics' needs and teach them skills and knowledge crucial for effective functioning in the English-speaking academic environment (Frumina \& West, 2012, pp. 57-58).

Once the need was identified, it was then thoroughly explored in a survey conducted by the British Council in 2012 in which 217 university teachers and researchers participated. In the self-assessment survey it was found out that the average level of the participants was B1 according to CEFR, with reading slightly more advanced than other skills. Language subskills necessary for effective communication in academic environment were identified. Examples of these include searching for relevant journals online, reading academic articles and calls for papers, listening to presentations and participate in discussions, socialising and presenting at conferences. The types of products academics need to be able to create were found out to be e-mails, grant proposals, reviews, abstracts, and journal publications. All these determined the contents of the course (contextual realisation) and the activities designed around texts (pedagogical realisation).

When the 'English for Academics' course was created, the 'materials evaluation' phase coincided with the 'students' use of materials' phase. Tomlinson (2011, p. 174) claims that 'materials need to be monitored by the author(s), by other 'experts' not involved in the writing team and by typical users of the material'. A 'fresh' look allows to identify the drawbacks which stay unnoticed by the authors as their vision is blunted by familiarity. Amrani (2011) describes three methods normally used to evaluate materials: piloting, reviewing, and focus groups. In case of the 'English for Academics' project, piloting was chosen, i.e. trial of materials in real classrooms. The advantages of piloting are opportunities to use materials in genuine settings and to adapt them to better meet learners' needs.

Two questionnaires were developed to get feedback from the participants. Both learners and teachers could leave comments in each category. The use of questionnaires has apparent benefits. They are easy to administer and to analyse, provide researchers with a significant body of data, allow respondents to keep anonymity and, therefore, be truthful in their responses. However, a questionnaire should ideally provide an opportunity for comments and open responses as 'they allow additional potentially relevant information to emerge' (Lake, Long, \& Serafini, 2015, p. 124.) That is why questionnaires with an openanswer option were used both at the initial stage of the discovery of learners' needs, and at the piloting stage with the purpose of learning and teaching materials evaluation.

In this paper, it is going to be illustrated that the understanding of learners' needs is not confined to the identification of needs stage, but it penetrates the book writing process. In addition, it will be demonstrated that not only learners', but also teachers' needs can be found in the process.

\section{Procedure}

As it has been mentioned, the essential learners' needs, i.e. the microskills they need to master to successfully function in the academic environment and the texts they have to deal with, were identified at the first stages of the project. However, the materials evaluation stage, piloting in this case, gave the authors an opportunity to discover more needs and to redesign the materials in accordance. The contents of the piloting materials included two lessons from each Module. The two Writing lessons were dedicated to abstract and grant proposal writing.

What teachers and learners were asked to assess were:

1. Timing

2. Difficulty of materials

3. Relevance

4. Variety

5. Clarity of instruction (classrooms materials)

6. Clarity of guidance (teachers' notes)

7. Language support

8. Visuals

9. Sequencing

10. Learners' motivation

All in all, 56 teachers and 378 learners at universities in Russia and former Soviet republics evaluated the materials. The learner cohort was rather heterogeneous in terms of field of study. The learners were from humanities (linguistics, philology, cultural studies), social sciences (economics, sociology, history), and hard sciences (mathematics, physics, chemistry, biology). They were $\mathrm{PhD}$ students, university lecturers and several representatives of administrative staff, all adults aged above twenty.

Both teachers and learners were encouraged to complete the evaluation survey and to give verbal qualitative feedback in the written form, the learners gave their evaluations in Russian and the teachers in English. However, not every teacher managed to cover all four modules with the classes, therefore, the 
number of responses in each section may differ. The responses, both qualitative and quantitative, were analysed and some conclusions were drawn about how materials should be reworked.

\section{Results}

\section{General Feedback}

Overall, the feedback was positive and included comments like:

In general, the course is highly relevant and unique in its context. No doubt, I'll be using it when it is released.

As I have mentioned before, the material is topical for the learners and corresponds with their needs, thus they were interested and highly-motivated to work with it and obtain necessary knowledge.

The students were highly motivated by the course, they participated in class work actively, and evaluated the course positively. The materials are authentic, relevant to the fields of students' specialisations and reflect the current issues in academia.

These materials are exactly what I need for a group of highly motivated adults studying English for academic purposes.

The materials preset an opportunity for the teacher to develop the language skills using highly authentic and motivating materials. I didn't have to motivate or encourage the learners as they were motivated by the material itself. So, I did enjoy the process of teaching. Besides, the material seemed to be interesting and useful for myself as a teacher and a researcher.

The quality of the materials is excellent and relevant for University teachers. I appreciate a lot the use of authentic texts, modern teaching approaches and techniques, IC technology support.

The Writing Module was positively evaluated as well:

They [the learners] were especially motivated by the tasks connected with abstracts and grants.

The writing part is very logical and clear, it explains all the steps and stages of writing abstract or other paper. All the parts I worked with were interesting and corresponding with the learners' needs.

The Writing and Reading sections are structured in a good way and the choice of topics and functions is very good.

However, some inconsistencies and flaws in the materials alongside with learners' and, what is equally important, teachers' needs were revealed. The questionnaire format made it possible to understand exactly where a difficulty or a misunderstanding lies and to redesign the materials to bridge the gaps and to correct the flaws.

\section{Timing}

Each module (skill) was evaluated separately though the participants were also encouraged to describe the overall impression.

For categories 'Timing', 'Difficulty of materials', 'Relevance' and 'Variety' the answer options included:

1. Completely unsuitable for my class

2. Of limited value for my class

3. Suitable for my class but with some reservations

4. Suitable for my class in most respects

5. Ideal for my class

Figure 1 represents the teachers' evaluation of timing, i.e. the possibility to cover the given material within the allocated period of time. Although the majority of teachers rated the materials as "suitable for my class in most respects” (48\%), some concerns were brought to light.

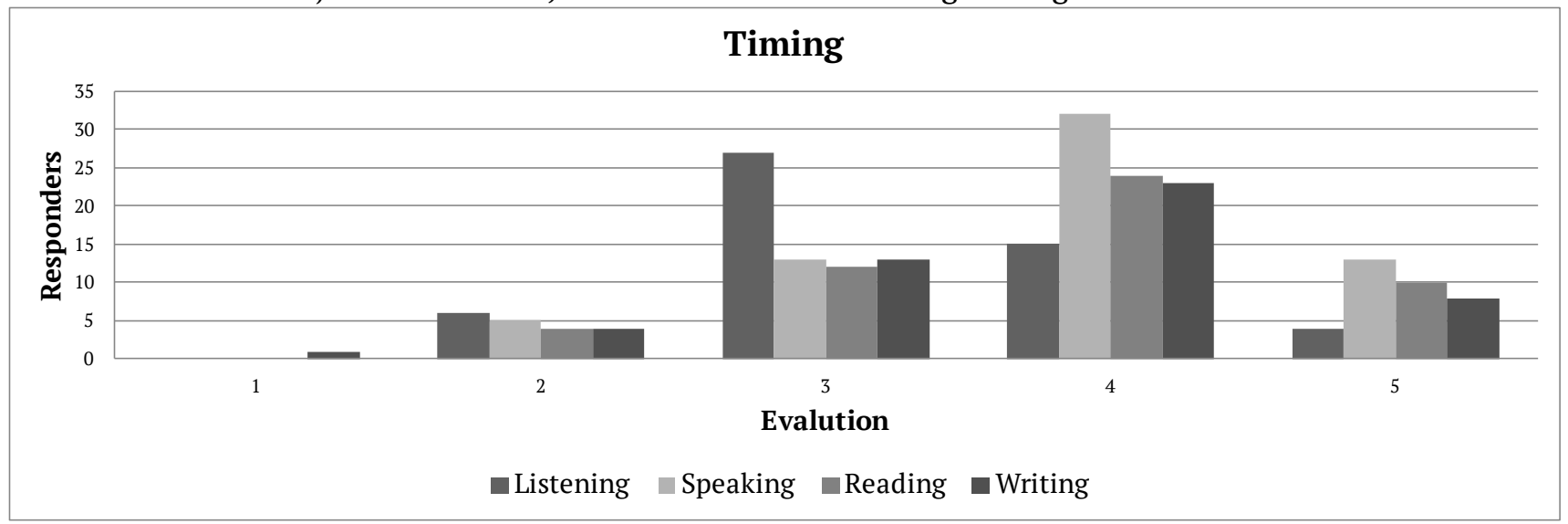

Figure 1. Timing: amount of material for the time available (teachers' response; from 1 - "completely unsuitable for my class" to 5 - "ideal for my class"). 
Some teachers expressed concerns about students' inability to cover all the materials included in one lesson within the 45-minute period, especially with mixed-level groups. Though in the Writing Module learners were required to create the draft of their written product in class and then self- or peer-assess it according to the set criteria, it was not always possible to do so. One of the teachers, for instance, reported that 'Writing seemed to coincide with the participants' perception of their level, however timing became an issue, as some participants required slightly more time for writing an abstract'. One of the respondents commented that peer-evaluation of a draft is one of the most useful and interesting tasks. However, there were learners and teachers who requested such tasks to be set as homework. As one of the teacher respondents wrote, Writing is good, although it's rather difficult to persuade the learners to write in class they consider it to be a waste of time - they seem to need to discuss things in class rather than 'waste' time writing - they want this part (I mean writing with a pen) to be done as home assignment.

As such misunderstanding of methodology was revealed, the approach taken was explained in Teachers' Notes. In the course, the attempt was made to combine product and process approaches to writing. The product approach implies studying a model text, analysing its structure and linguistic features, drilling them, and producing own text at the final stage. The process approach involves scaffolding of the writing process, from collaborative generation of ideas and their organisation to drafting, assessment and redrafting. An option was suggested that the writing of the draft can be done as homework, while peer-assessment can take place at the lesson that follows.

\section{Relevance}

The participants were also encouraged to evaluate the relevance of the materials subject to piloting and to identify if they were appropriate for researchers from various fields of study. The result of this evaluation is summarized in Figure 2.

Although the majority of teachers assessed this aspect highly, teachers and learners whose specialism was science asked for more texts from their areas of interest. Originally, the authoring team consented on the pedagogical exploitation of texts which discuss the issues of modern pedagogy and the use of technology in the classrooms. The result was, scientists not involved in teaching could find these materials irrelevant:

The emphasis put on the Humanities in the material for all sections is too obvious. I strongly recommend to use a variety of fields, as academic staff from technical and scientific institutions will NOT be happy to deal with language and social sciences throughout the whole of the book. This is a very strong recommendation from both me and my students.

That was the reason for the inclusion of texts both from humanities and hard sciences with appropriate easification. For instance, some texts are supported with glosses, challenging vocabulary and structures are pre-taught, schemata is activated before actual reading (for more information on easification see [Bhatia, 1983]). It gave the authors an opportunity to highlight the difference in structure and language of texts from different disciplines.

\section{Clarity of Instructions}

For other categories, teachers and learners could evaluate the materials as 'Poor' - 1 , 'Not very good' - 2 , 'Adequate' - 3, 'Good' - 4, or 'Excellent' - 5.

Unexpectedly, the instructions posed difficulty for the teachers (Figure 3). The concerns included:

- long and complex sentences;

- intricate wording which inhibited understanding;

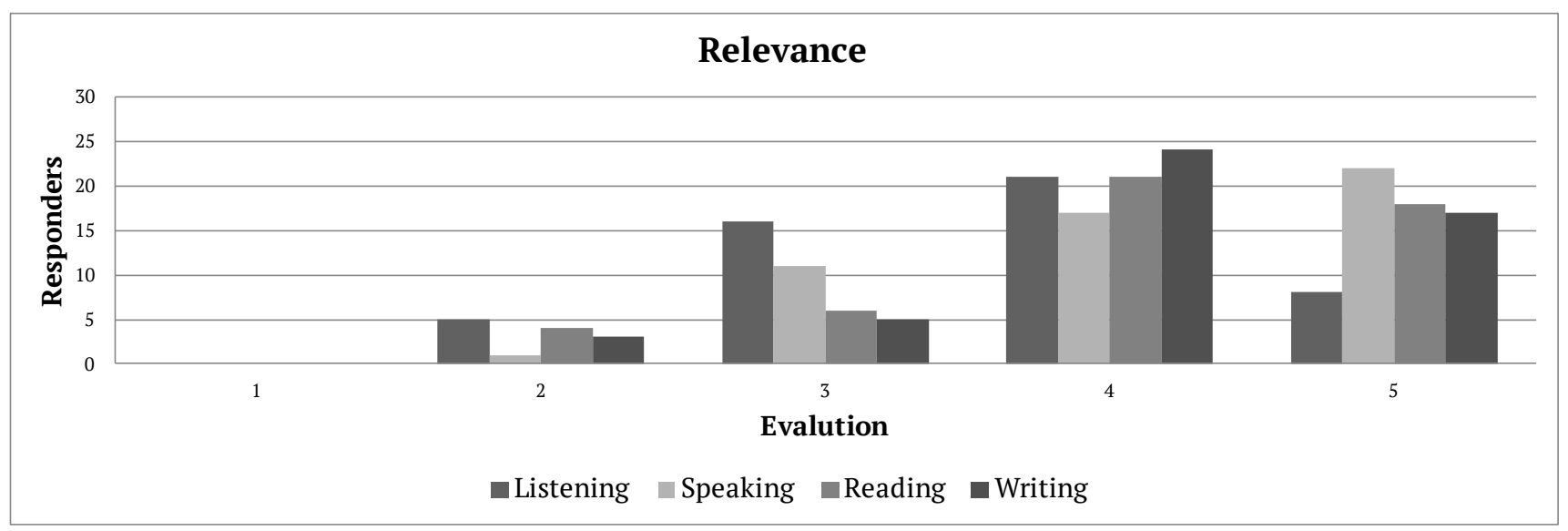

Figure 2. Relevance: content areas covered (teachers' response; from 1 - “completely unsuitable for my class" to 5 - "ideal for my class"). 
- unclear reference to other activities.

One teacher recommended 'to go into less detail in instructions and more straight to the point of the task'. Another one said that 'it's difficult to figure out from the wording of the task what exactly should be done'. It was noted in teachers' responses that 'you have to read tasks very carefully to understand what is required and, for example, which of the previous tasks that one refers to'.

Based on teachers' evaluation, flaws and inconsistencies in instructions were corrected. Moreover, instructions were easified in terms of language and structural complexity, that is, we opted for shorter and easier structures and the vocabulary of a lower level. For instance, the instruction 'Among the words in bold in the summary above find equivalents to the expressions in Column A in the table below' was changed to 'Match the highlighted words in the abstract to their synonyms 1-10 below'. In some cases it was necessary to get rid of wordiness and to make instructions concise. Thus, 'Here are 7 steps for writing an abstract. They are jumbled. Number them in a logical order' became 'Put these steps for writing an abstract in order'. Overall, it was decided within the group to: 1. make instructions uniform throughout the book according to the pattern imperative+what +how; 2 . assign one task per instruction; 3 . provide numerical references.

\section{Language Support}

There was no univocal evaluation of language support, namely, the way grammar, functions and vocabulary were introduced and practiced as shown in Figure 4.

Some teachers were quite positive about it saying that:

Most texts are a valuable source of both information and language for the learners. I liked grammar and vocabulary as well as visuals. It is very convenient to work with charts especially if you have to compare or contrast something.

However, there definitely was room for improvement as some respondents expressed the following concerns:

As for the guidance, it was excellent, while language support, to my mind, very often was inefficient: the vocabulary was given, but grammar and functions most often weren't.

According to our observation of the Ls' responses, we felt that there could have been more material in terms of Language support, e.g. more extended focus on Advanced Academic Vocabulary, which was perceived to be needed for the productive skills, i.e. Speaking and Writing.

The students reflect that there is not enough language support, especially some grammar activities on the Passive Voice.

As for the writing, there should be "letterswriting' exercises, exercises to support and drill linking words.

To satisfy those needs, more activities were developed and introduced. These tasks were aimed at the development of learners' linguistic competence, in terms of reception and production, and they also included strategy training and microskills development (such as using appropriate word order, or achieving cohesion and coherence in writing).

One more issue related to language support was the misunderstanding of the approach in which grammar and vocabulary were introduced. In many cases the authors followed the language awareness approach, which implies conscious concentration on how linguistic features function in context (for more information see (Bolitho et al., 2003)). Allegedly, university professors and researchers are learners with

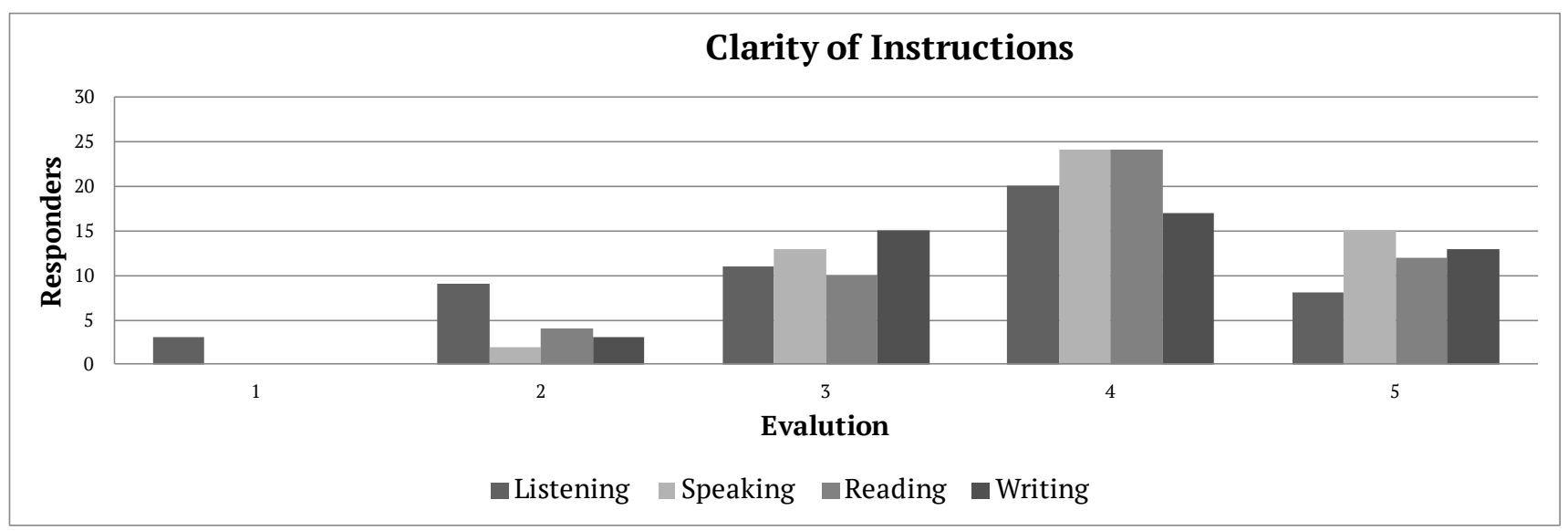

Figure 3. Clarity of instructions in Learner's Material (teachers' response; from 1 - "poor" to 5 - “excellent”). 
developed cognitive skills and logic. Though there were teachers who realised that the "materials are based on such methodological principle as a conscious approach' to the development of the linguistic competence, some teachers complained that 'Not fewer than $80 \%$ of the students are not accustomed to working in the proposed cognitive methodology and it needs time to explain the logics of almost each exercise'.

It was even suggested that 'logical sequencing of tasks should also be revised, especially for reading and writing - vocabulary, grammar, style support should come before the task'.

- To resolve the misunderstanding it was decided, firstly, to briefly outline the necessary theoretical information about the approach in Teachers' Notes, and, secondly, to provide activities for learners' strategic training to teach them strategies to research the context for the meaning of linguistic features.

\section{Summary of Teachers' Feedback}

To sum up, teachers expressed the need for clearer instructions, more grammar and vocabulary practice for their learners, methodological clarifications both for teachers and learners, variety in texts and activities. More suggestions given by the teachers who participated in the piloting were the requests:

- to have a glossary of academic vocabulary

- for the teacher's book to have materials for further practice and comments for the teachers, explanation of some specific academic terms, possible answers for open questions ('teachers need more general guidelines: strategies, techniques approaches, ideas for practice activities but not very detailed step by step instruction')

- for the student's book to have more visuals ('that could help with understanding the content').

\section{Learners' Feedback}

Learners were also encouraged to give quantitative and qualitative feedback on the materials they tried in the classroom. On the whole, learners were motivated by the materials $(91,8 \%)$ as they were interesting and up-to-date and the skills the participants gained could find application in their professional lives. The participants reported on having learnt new vocabulary and expressions, understanding style requirements and academic conventions (95\%).

However, open responses assisted in uncovering problematic areas and discovering learners' pedagogical needs, for instance:

Sometasks required additional explanations on the teacher's part.

We did not have enough time to do all the activities, especially in the Writing section. It would be useful to have a vocabulary list for each lesson.

Vocabulary was difficult, I had to turn to the dictionary rather often.

Variety could be achieved if the scope of materials is widened.

Learners' open responses were analysed and the most frequent concerns are summarised in Figure 5.

As it can be seen, the concerns expressed by the learners are very similar to what the teachers pointed out. Though the learners evaluated the materials as relevant and practical, requests were expressed to make materials and exercises more varied, to include texts from other fields apart from pedagogy and humanities, and to provide more activities for the practice of academic vocabulary. As for difficulty of materials, some learners found them too challenging and some too easy. Such discrepancy in opinions may be dictated by the heterogeneity of the pilot groups since a number of teachers reported having both A2 and $\mathrm{C} 1$ learners in their classes.

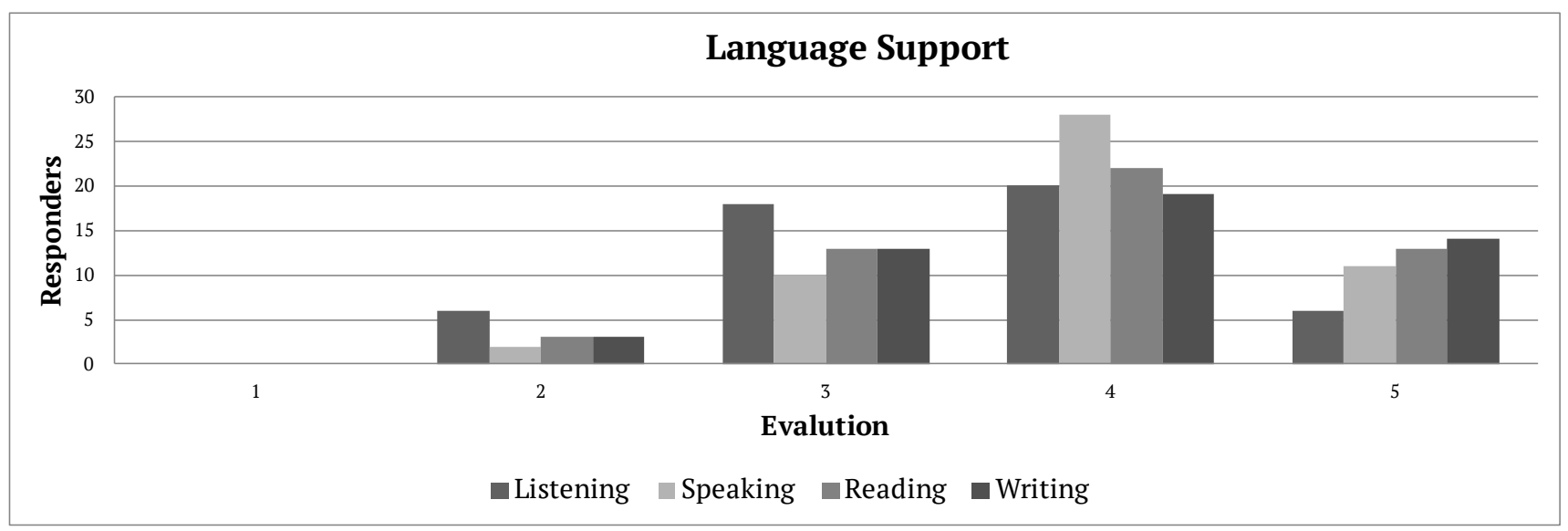

Figure 4. Language support (grammar, functions, vocabulary) (teachers' response; from 1 - “poor" to 5 - “excellent”). 


\section{Discussion}

However important needs analysis may be, its methodological potential is still under-researched (Long, 2005, p. 2). There are a number of studies demonstrating the ways in which needs analysis can be carried out. Among the most recent ones is Serafini, Lake and Long's (2015) article, describing the needs analysis procedure among non-native speakers of English who are part of the scientific community at a large university. In this case, an open questionnaire aimed at identifying the tasks such in-service learners fulfil was supplemented by structured interviews, activity journals, discourse analysis, observations. In another recent study Balzhiser et al. (2015) used focus group discussions and questionnaires to create a target learner profile for a Ph.D. course aimed at working professionals. Helmer (2013) compared data obtained through questionnaires administered to students and tutors, interviews and observations. In addition, institutional resources were analysed, and on the basis of the above, changes were introduced to the Academic Writing programme. In an earlier study by Read (2008), diagnostic assessment was used for the purpose of understanding students' academic needs and providing appropriate academic support. According to Serafini, Lake and Long (2015), 10 needs analysis studies of 1980s-1990s predominantly relied on questionnaire surveys, interviews and observations.

This article contributed to the body of methodological options for needs analysis and describe how piloting can be utilised for needs analysis purposes. Moreover, teachers' needs and concerns were uncovered.

To add to that, though the materials were positively evaluated when they were piloted, the evaluation stage disclosed the needs which were not discovered at the exploration of needs stage, which, in its turn, led to considerable amendments to learning and teaching materials.

As the needs for more techniques, ideas for additional activities, possible answers for open questions, explanation of terminology in Teachers' Notes were expressed, they were considerably reworked.Firstly, the pedagogical principles underlying the structure and logic of materials, such as process and product approaches to writing or the language awareness approach were explained. Secondly, extra activities for the reinforcement of skills and extension of knowledge were added. Thirdly, some academic terms were clarified. Finally, options were provided for mixed-level groups.

Based on the issues revealed, the following changes were introduced into the textbook:

- more activities for grammar and vocabulary practice were added, as well as some activities to develop particular writing microskills

- instructions were considerably reworked with the purpose of making them clear and concise

- an academic vocabulary list which included lexis practised within the book was added

- texts (e.g. abstracts) from different fields of study were added, and the linguistic and structural difference was highlighted and

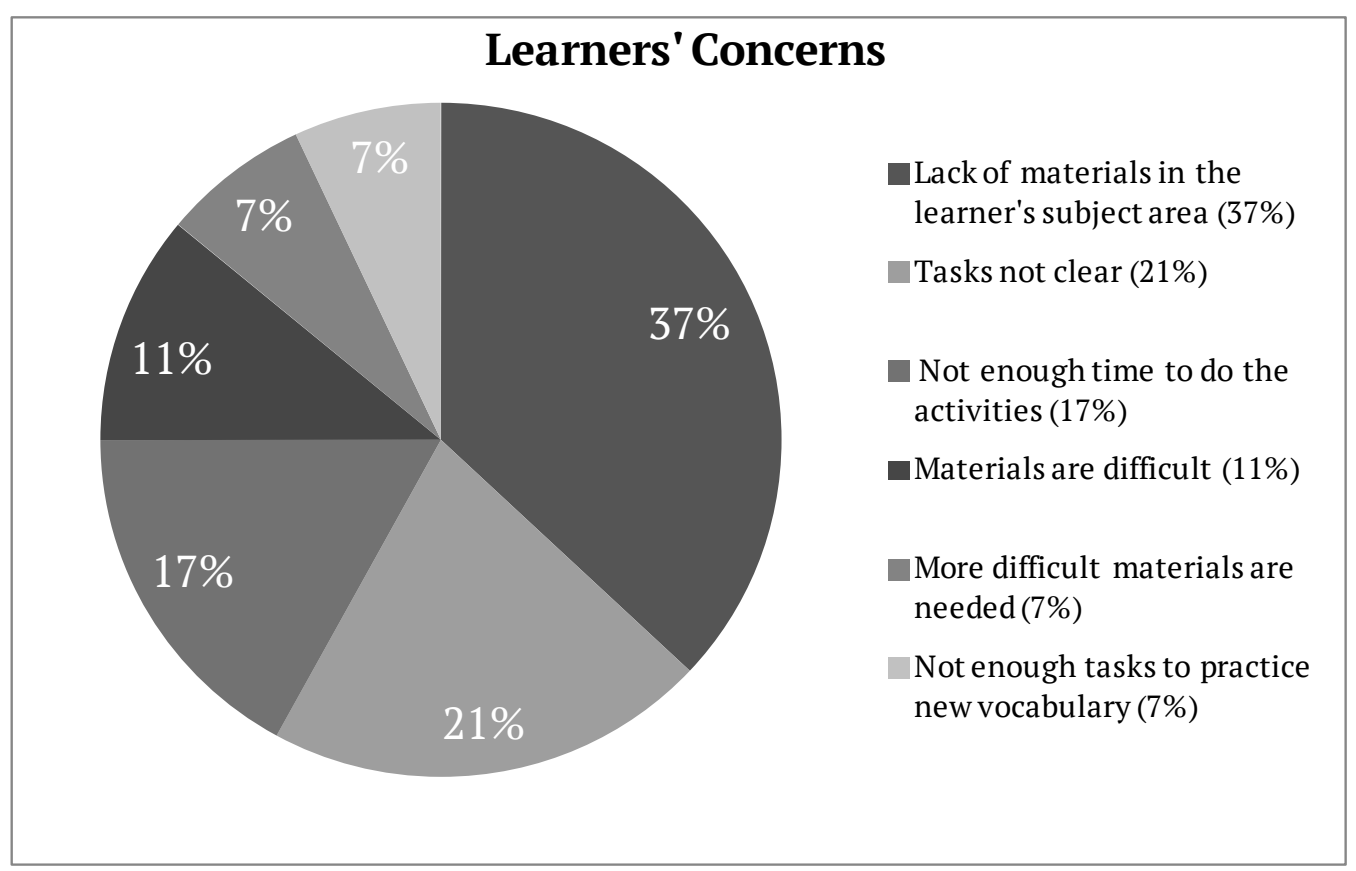

Figure 5. Concerns expressed by learners (72 responses). 
practiced.

On the whole, the evaluation stage not only exposed flaws in learning materials, but also let the authoring team recognise additional needs of the target audience and restructure materials to meet these needs. Moreover, the requests were taken into account when the second book in the course was created (Bogolepova et al., 2015).

\section{Conclusion}

Though the needs analysis stage normally precedes the materials development stage, the 'English for Academics' experience clearly demonstrated that the trial of materials in real classrooms gives the developers an opportunity to further explore the needs of the target group of learners. Moreover, the needs and expectations of potential instructors can be identified. Hyland (2006, p. 74) argues that it would be accurate 'to see needs as jointly constructed between teachers and learners,' which piloting allows material developers to achieve. The feedback from the project consultant and the editor was no less valuable and taken into account, and, consequently, triangulation was provided for.

Additionally, piloting gave the materials designers the opportunity not only to identify the microskills to master but also to expose pedagogical needs such as clarity of instructions, diversity in texts and tasks, as well as misinterpretations of underlying pedagogical principles. Thus, needs analysis penetrated the textbook writing process and allowed for the exploration of needs in different dimensions and from different perspectives.

\section{Acknowledgments}

Gratitude is expressed to the British Council, Moscow, for the permission to use and analyse the survey results and all the respondents for the participation in the survey.

\section{References}

Amrani, F. (2011). The process of evaluation: A publisher's view. In B. Tomlinson (Ed.), Materials development in language teaching (pp. 267-295). Cambridge, UK: Cambridge University Press.

Balzhiser, D., Sawyer, P., Womack-Smith, Sh., \& Smith, J. A. (2015). Participatory design research for curricilum development of graduate programmes for workplace professionals. Programmatic
Respectives, 7, 79-133.

Bezzabotnova, O., Bogolepova, S., Gorbachev, V., Groza, O., Ivanova, A., Kuzmina, T., \& Suchkova S. (2014). English for academics (Book 1). Cambridge, UK: Cambridge University Press.

Bhatia, V. K. (1983). Simplification vs. easificatiom - The case of legal texts. Applied Linguistics, 4(1), 42-54.

Bogolepova, S., Gorbachev, V., Groza, O., Shadrova, E., Suchkova, S., Kuznetsova, L., \& Pervukhina, I. (2015). English for academics (Book 2). Cambridge, UK: Cambridge University Press.

Bolitho, R., Carter, R., Hughes, R., Ivanic, R., Masuhara, H., \& Tomlinson, B. (2003). Ten questions about language awareness. ELT Journal, 57(3), 251-259.

Flowerdew, L. (2013). Needs analysis in curriculum development in ESP. In B. Paltridge \& S. Starfield (Eds.), The handbook of English for specific purposes (pp. 325-346). Malden, MA: Wiley-Blackwell.

Frumina, E., \& West, R. (2012). Internationalisation of Russian higher education: The English language dimension [Adobe digital editions version]. Retrieved from http://www.britishcouncil.ru/ sites/default/files/internationalisation_of_russian_ higher_education.pdf

Hamp-Lyons, L. (2001). English for academic purposes. In R. Carter \& D. Nunan (Eds.), The Cambridge guide to teaching English to speakers of other languages. Cambridge, UK: Cambridge University Press.

Helmer, K. (2013). Critical English for academic purposes: Building on learner, teacher, and programme strengths. Journal of English for Academic Purposes, 12, 273-278.

Hutchinson, T., \& Waters, A. (1997). English for specific purposes. A learning-centered approach. Cambridge, UK: Cambridge University Press.

Hyland, K. (2006). English for academic purposes. London, UK: Routledge.

Hyland, K. (2009). Teaching and researching writing. Harlow, UK: Pearson Education Limited.

Hyland, K., \& Hamp-Lyons, L. (2002). EAP: Issues and directions. Journal of English for Academic Purposes, 1, 1-12.

Jolly, D., \& Bolitho, R. (2011). A framework for materials writing. In B. Tomlinson (Ed.), Materials development in language teaching (pp. 107-134). Cambridge, UK: Cambridge University Press.

Jordan, R. R. (1997). English for academic purposes. Cambridge, UK: Cambridge University Press.

Jordan, R. R. (2002). The growth of EAP in Britain. Journal of English for Academic Purposes, 1, 69-78.

Lake, J., Long, M., \& Serafini, E. (2015). Needs analysis for specialized learner populations: Essential methodological improvements. English for Specific Purposes, 40, 11-26.

Long, M. (2005). Second language needs analysis. 
Cambridge, UK: Cambridge University Press.

Read, J. (2008). Identifying academic language needs through diagnostic assessment. Journal of English for Academic Purposes, 7, 180-190.

Richards, J., \& Schmidt, R. (2010). Longman dictionary of language teaching and applied linguistics (4th ed.). London, UK: Pearson.
Serafini, E., Lake, J., \& Long, M. (2015). Needs analysis for specialized learner populations: Essential methodological improvements. English for Specific Purposes, 40, 11-26.

West, R. (1994). Needs analysis in language teaching. Language Teaching, 27(1), 1-19. 